\title{
Morphometric Investigation of the Sacral Bone in MR
}

\section{Images}

\author{
Seher Yilmaz ${ }^{1}$, Adem Tokpinar ${ }^{1}$, Niyazi Acer ${ }^{2}$ and Serap Doğan ${ }^{3}$ \\ 1. Department of Anatomy, Faculty of Medicine, Yozgat Bozok University, Yozgat 66900, Turkey \\ 2. Department of Anatomy, Faculty of Medicine, Erciyes University, Kayseri 38150, Turkey \\ 3. Department of Radiology, Faculty of Medicine, Erciyes University, Kayseri 38150, Turkey
}

\begin{abstract}
Introduction and purpose: The sacrum is an important bone structure involved in the field of fusion and stabilization in the treatment of sacral bone, lumbosacral and sacroiliac deformities or injuries. The aim of this study is to determine the mean index values of some parameters in the sacrum according to age and gender in certain age groups and to contribute to the literature. Materials and Methods: In this study, measurements were made using 3D CT images of the sacrum in patients who were admitted to Erciyes University Gevher Nesibe Hospital for various complaints and underwent lumbar CT. Totally, 166 men and 144 women aged 10-50 years were included in the study. The mean index values of the sacral length, sacral width, sacral angle, hiatal length, hiatal width and hiatal angle were determined. Angle measurements were performed using the ImageJ, a Java-based image processing program. Findings: When we compare the data in our study, we found a significant difference in the mean hiatal length between men and women $(p<0.05)$. The mean sacral length was $112.69 \pm 16.61 \mathrm{~mm}$ in men and $105.58 \pm 15.18 \mathrm{~mm}$ in women, respectively. Sacral width was found to be $109.93 \pm 10.51 \mathrm{~mm}$ in men and $110.63 \pm 10.48 \mathrm{~mm}$ in women. Conclusion: There was no significant difference in sacral length, sacral width, sacral angle, hiatal width, hiatal angle measurements in male and female and there was no significant difference between hiatal length.
\end{abstract}

Key words: Sacrum, morphometry, sacral hiatus, sacral cornua.

\section{Introduction}

The pelvis is made up of four bones connected together by means of slightly movable joints: two hip bones, plus the sacrum and the coccyx. Each hip bone contains three fused bones: the ilium, the ischium and the pubis. The pelvis is responsible for the transfer of load between the spine and lower limbs. The sacrum is a large, triangular bone formed by the fusion of five sacral vertebrae. It is situated in the lower part of the vertebral column and at the upper and back part of the pelvic cavity. Its apex articulates with the coccyx and its base articulates with the fifth lumbar vertebra at the lumbosacral angle [1,2].

Sacral hiatus is the opening present at the caudal end of sacral canal formed by the nonfusion of the lamina

Corresponding author: Seher Yilmaz, PhD, Asst. Prof. Research fields: Stereology, Anatomy, Cancer. of the fifth (occasionally fourth) sacral vertebra. Injections and catheterizations performed on this region are used for regional anesthesia and analgesia especially in children, adults and pregnant women. The sacral hiatus is absent in $7.7 \%$ of population. However, the success rate of CEB (caudal epidural block) is $94 \%$. It is important to know the topographical structure of this region during this process [3].

As reported by various authors, the reliability and success of caudal epidural anesthesia depend on the anatomical variations of the sacral hiatus [4-6]. Also the importance of the spine is great in analyzing posture [7]. This abnormality is clinically important for the CEB, which is usually performed in the diagnosis and treatment of lumbar spine disorders. Sacral intervertebral approach to the epidural space is preferred to provide analgesia and anesthesia in many operations such as the prevention of chronic back pain 
and the treatment of lumbar spinal disorders $[8,9]$. In addition, the preservation of neural structures in surgical interventions performed in this region is clinically important. Therefore, having a good knowledge of the normal anatomic structure and morphometric values of the sacrum helps physicians in preventing possible complications during operations performed in this area. Care must be taken in entering the canalis sacralis in order to prevent puncture of the dural sac and to protect surrounding structures [10].

Spina bifida has been present as long as man has walked the planet. A number of anthropological excavations have uncovered spines with stigmata typically seen in infants born with myelomeningoceles [11]. In fact, psina bifida is a central nervous system disease resulting from inadequate closure of the neural tube between 22 and 28 weeks of gestation. It is in second place after cerebral palsy among neurodevelopmental disorders that may be seen in childhood [12]. Pediatric spinal cord injury does not deteriorate over time, but continues throughout life [13].

\section{Materials and Methods}

In our study, measurements were made using 3D CT images of the sacrum in 144 women and 166 men aged 10-50 years. CT images were examined by a specialist from the Department of Radiology at Erciyes University Medical Faculty (Figure 1). Patients without any sacral pathology on images according to this radiological examination were included in the study. Angle measurements were performed using the ImageJ that is a Java-based image processing program developed by the National Institutes of Health (Figure 2).

The hiatal angle was measured by calculating the angle between the lines drawn from the sacral cornua to the apex of the sacral hiatus (Figure 3). The sacral angle was measured by calculating the angle between the lines descended from the most prominent region of crista iliaca to the apex ossis sacri.

The hiatal length was measured between the apex of the sacral hiatus and the sacral cornua. The hiatal width was measured as the widest distance of the two sacral cornua (Figure 4).

\subsection{Statistical Analysis}

The fit of data to the normal distribution was assessed by histograms, q-q plots and Shapiro-Wilk test. The homogeneity of variance was examined by the Levene's test. In binary comparisons, the independent two-sample $t$-test and Mann-Whitney $U$ test were used for quantitative variables. The data were analyzed with the R 3.2.2 software (www.r-project.org). A p-value of $<0.05$ was considered statistically significant.

\section{Findings}

The mean sacral length was $112.69 \mathrm{~mm}$ in men and $105.58 \mathrm{~mm}$ in women, respectively. The mean sacral angle was $65.59^{\circ}$ in men and $64.21^{\circ}$ in women, respectively. The mean hiatal angle was $35.80^{\circ}$ in men and $35.48^{\circ}$ in women, respectively. The mean sacral width was $109.93 \mathrm{~mm}$ in men and $110.63 \mathrm{~mm}$ in women, respectively. The mean hiatal width was 14.92 $\mathrm{mm}$ in men and $12.90 \mathrm{~mm}$ in women, respectively. The mean hiatal length was $32.00 \mathrm{~mm}$ in men and 25.32 $\mathrm{mm}$ in women, respectively (Table I-IV).

While there was no significant difference between the hiatal angle, hiatal length, sacral length, sacral width and sacral angle in the 20-29 age group, there was a significant difference between them in the hiatal width (Table II).

\section{Discussion}

Studies on the sacrum in the literature are usually performed on dry bone and direct radiographs. In our study, measurements were made by computerized tomography according to age groups and genders.

Başaloğlu et al. [10] examined 60 dry adult bones. They found that the mean sacral height was respectively $10.20 \pm 1.02 \mathrm{~cm}$ in women and $10.43 \pm$ $1.24 \mathrm{~cm}$ in men and that there was no significant difference between women and men $(p>0.05)$. In our 
study, it was found that the sacral length was between $11.2 \mathrm{~cm}$ in men and $10.5 \mathrm{~cm}$ in women, respectively. No statistically significant difference was found between men and women.

Emirzeoğlu et al. [14] examined 32 dry bones regardless of gender. They reported that the mean sacral height was $10.27 \mathrm{~cm}$. These results are similar to our results.

Mishra et al. [15] examined 116 dry sacral bones (74 men and 42 women). They calculated that the mean sacral height was respectively $107.53 \mathrm{~mm}$ in men and $90.58 \mathrm{~mm}$ in women. In our study, it was found that the mean sacral length was $112.69 \mathrm{~mm}$ in men and 105.58 $\mathrm{mm}$ in women, respectively. The men's measurements were very close to each other, while the women's measurements were different from each other. It is estimated that this difference may be racial.

Tolga et al. [16] calculated that the mean sacral height was respectively $10.78 \pm 0.92 \mathrm{~cm}$ in women and $11.67 \pm 0.90 \mathrm{~cm}$ in men and that the mean sacral width was respectively $11.57 \pm 0.68 \mathrm{~cm}$ in women and 11.65 $\pm 0.72 \mathrm{~cm}$ in men. They found that there was no significant difference between women and men $(p>$ $0.05)$. These values are similar to our values.

Asher and Strippgen [17] made measurements manually on 18 cadavers ( 9 men and 9 women). They found that the mean sacral width was respectively $10.40 \pm 0.69 \mathrm{~cm}$ in men and $10.64 \pm 0.47 \mathrm{~cm}$ in women. They reported that there was no significant difference between women and men $(p>0.05)$.

Başaloğlu et al. [10] found that the mean sacral width was respectively $10.84 \pm 0.60 \mathrm{~cm}$ in women and $10.22 \pm 0.7 \mathrm{~cm}$ in men. They reported that there was a significant difference between women and men $(p=$ $0.001)$. In our study, it was found that the mean sacral width was $10.9 \mathrm{~cm}$ in men and $11 \mathrm{~cm}$ in women, respectively. No statistically significant difference was found between men and women.

Asher et al. [17] measured the sacrum width through the ala ossis sacri. They found that the mean sacrum width was respectively $10.40 \mathrm{~cm}$ in men and $10.64 \mathrm{~cm}$ in women.

In the study of Comas and Charles [18] involving Chinese, Black, African men and women, they reported that regional, racial, and gender differences may have an impact on morphometric measurements of the sacrum. Some different results may depend on methodological and material differences. Moreover, racial, nutritional, age, gender, genetic and socioeconomic differences among the individuals included in the studies on the sacrum can cause the results to be different from each other.

Esenkaya et al. [19] reported that anatomical variations as well as erosions especially in superficial, angular or end regions over time in dry bone specimens may be effective in numerical differences in morphometric measurements obtained on dry bone specimens.

Knowing the anatomical structure of the sacrum is very important for departments such as urology, gynecology, orthopedics, and anesthesia. The reasons for preferring caudal epidural anesthesia include low cost, early onset of bowel movements postoperatively, and reduced rate of venous or arterial thrombosis [20]. To achieve a successful caudal epidural anesthesia, the structure of the sacral hiatus should be determined for reaching the caudal epidural space [21-23].

Failure in CEB is mainly due to anatomical variations of the sacral hiatus. The closed sacral canal not being able to determine sacral canal due to spina bifda, absence of the sacral hiatus, divided bones in sacral hiatus, and narrow passage obstruct determining the location of sacral canal and therefore leading to unsuccessful CEB [24-26].

Ultrasonography is $100 \%$ successful in CEB but it is not every time possible due to time, cost and personal availability. So knowing the anatomical relations of the sacral hiatus will facilitate the procedure [27].

Distance from the apex of the sacral hiatus to the lower lumbar spinous processes is important to develop the techniques to prevent the neurological injury associated with the neuraxial injections [28]. 
Variations in the base of sacral hiatus have been detected by many authors and are described below. Most common level of base of sacral hiatus as detected by various authors is S5 vertebra [29, 30, 32].

$\mathrm{CEB}$ is done under the guidance of ultrasonography then the success rate is $100 \%$ but it is not always possible due to various reasons such as availability of instrument cost [31].

The variation found in the level of base of sacral hiatus may be due to varied sample size, specimen from various regions and also due to sacra from different sexes [33].

Ahmm et al. [34] examined 172 dry bones (91 men and 81 women). They calculated that mean hiatal length was respectively $26.38 \pm 12.02 \mathrm{~mm}$ in men and $25.63 \pm 10.46 \mathrm{~mm}$ in women. These results are similar to our results.

\section{Conclusion}

In our study, while there was no significant difference between the hiatal angle, hiatal length, sacral length, sacral width and sacral angle in the 20-29 age group, there was a significant difference between them in the hiatal width.

When our studies are compared with the studies in the literature, there are few differences in morphometric values and statistical results. Methodological, dietary, racial, socioeconomic and genetic differences can cause these different results.

The sacrum is clinically important in degenerative diseases and lumbosacral instabilities. Therefore, having a good knowledge of the normal anatomic structure and morphometric values of the sacrum may prevent possible complications during operations performed in this area. We think that our study will contribute to other surgery and anesthesia departments and also help minimize possible complications.

\section{Conflict of Interest}

The authors that there is no copnflict.

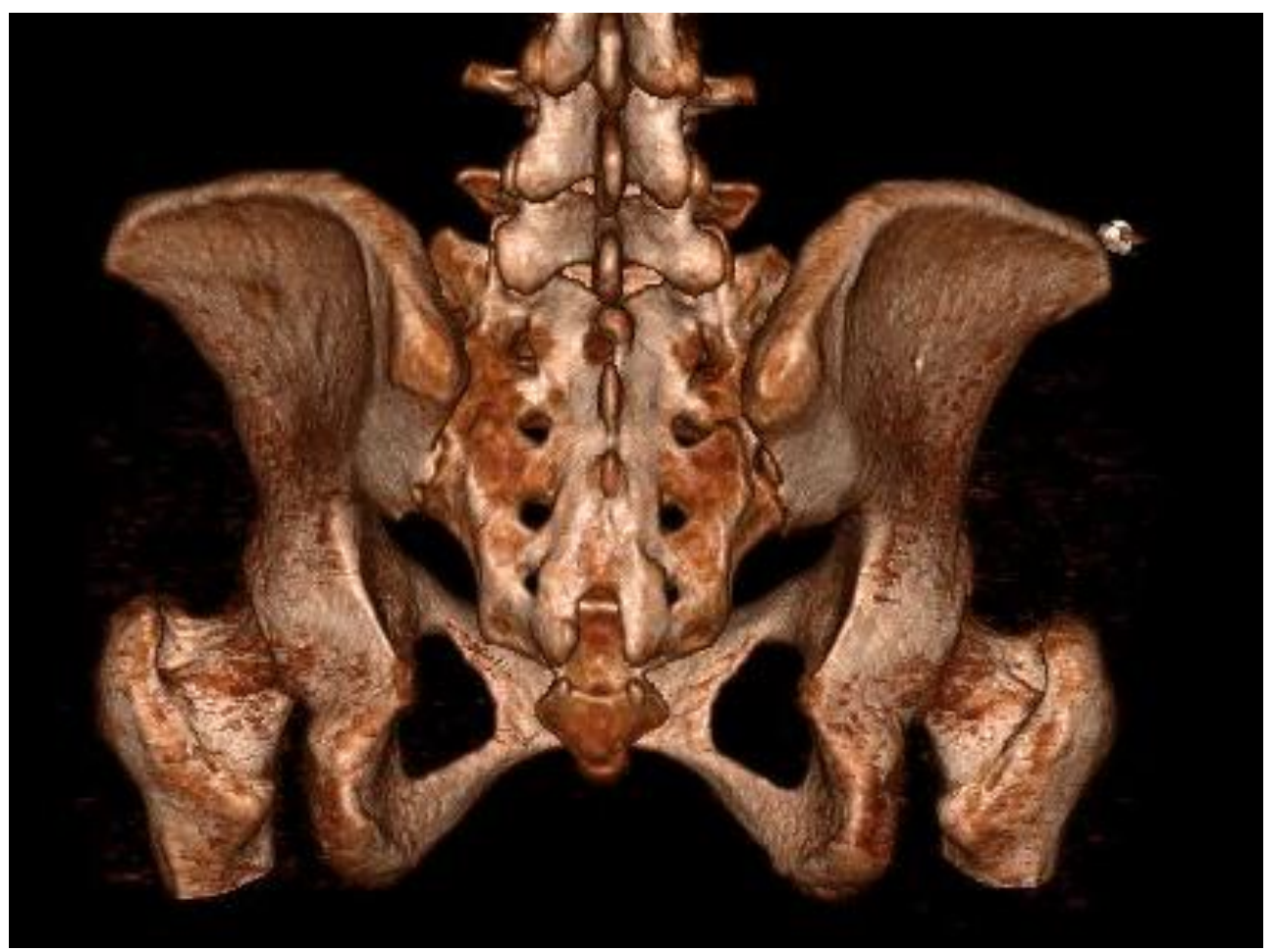

Fig. 1 Three-dimensional CT image used in the study. 


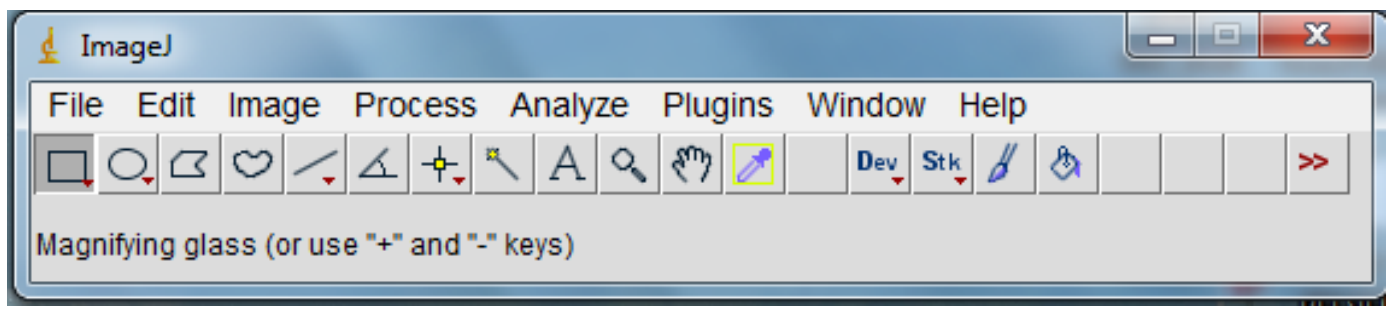

Fig. 2 An overview of ImageJ software.

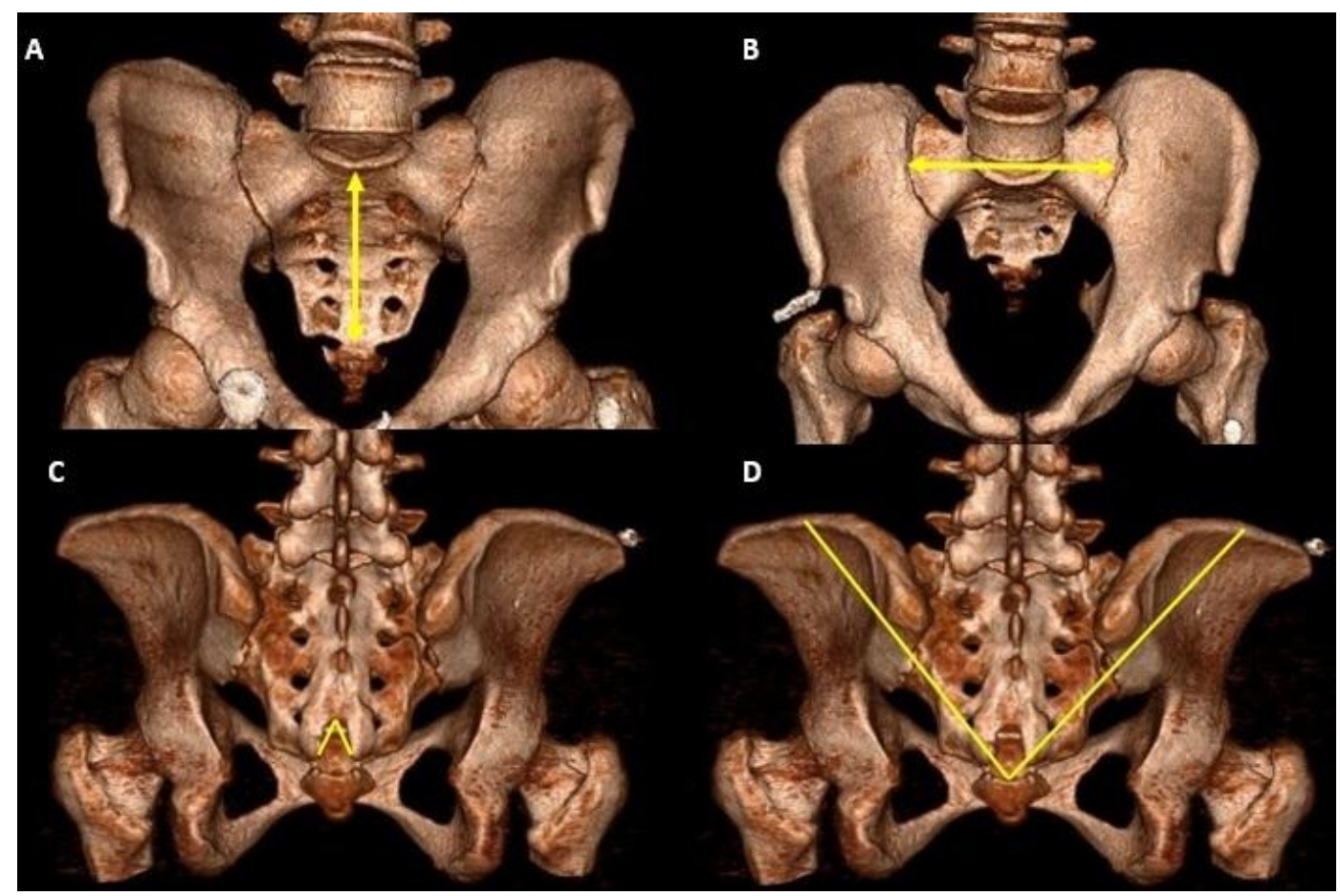

Fig. 3 (A) Sacral length; (B) Sacral width; (C) Measurement of hiatal angle; (D) Measurement of sacral angle.

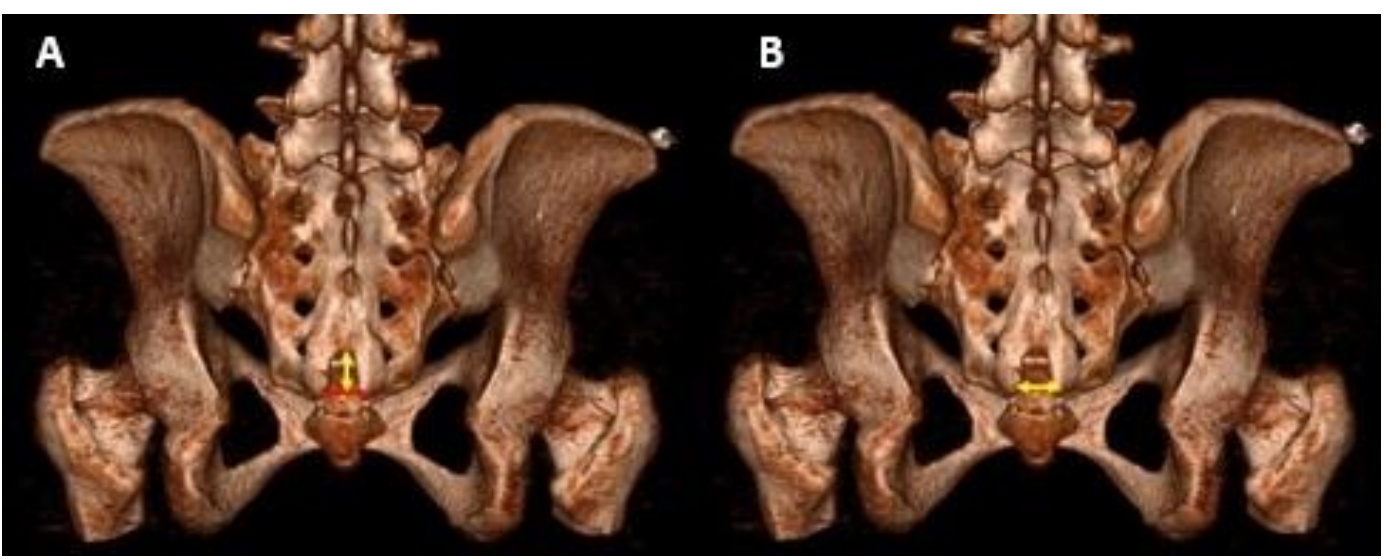

Fig. 4 (A) Hiatal length; (B) Hiatal width. 
Table 1 Measurement results on MR images between the ages of 10-19.

\begin{tabular}{llll}
\hline Variable & \multicolumn{2}{c}{ Gender } & $p$ \\
\cline { 2 - 4 } & Male & Female & 0.440 \\
\hline Sacral length $(\mathrm{mm})$ & $109.83 \pm 14.06$ & $104.60 \pm 15.17$ & 0.966 \\
Sacral width $(\mathrm{mm})$ & $99.12 \pm 11.82$ & $103.30 \pm 11.78$ & 0.310 \\
Sacral angle & $65^{\circ}$ & $64^{\circ}$ & 0.081 \\
Hiatal length $(\mathrm{mm})$ & $42.67 \pm 5.86$ & $26.17 \pm 4.17$ & 0.117 \\
Hiatal width $(\mathrm{mm})$ & $19.08 \pm 2.48$ & $13.20 \pm 3.62$ & 0.211 \\
Hiatal angle & $33^{\circ}$ & $33^{\circ}$ & \\
\hline
\end{tabular}

Table 2 Measurement results on MR images between the ages of 20-29.

\begin{tabular}{llll}
\hline Variable & \multicolumn{2}{c}{ Gender } & $p$ \\
\cline { 2 - 4 } & Male & Female & 0.787 \\
Sacral length (mm) & $116.23 \pm 13.26$ & $107.14 \pm 13.76$ & 0.881 \\
Sacral width (mm) & $107.02 \pm 6.53$ & $107.29 \pm 6.50$ & 0.699 \\
Sacral angle & $65^{\circ}$ & $64^{\circ}$ & 0.739 \\
Hiatal length (mm) & $31.88 \pm 4.07$ & $29.43 \pm 3.76$ & 0.037 \\
Hiatal width (mm) & $12.81 \pm 2.09$ & $11.99 \pm 2.31$ & 0.054 \\
Hiatal angle & $38^{\circ}$ & $35^{\circ}$ & \\
\hline
\end{tabular}

Table 3 Measurement results on MR images between the ages of 30-39.

\begin{tabular}{llll}
\hline Variable & \multicolumn{2}{c}{ Gender } & $p$ \\
\cline { 2 - 4 } & Male & Female & 0.492 \\
Sacral length $(\mathrm{mm})$ & $113.39 \pm 16.86$ & $103.44 \pm 13.53$ & 0.568 \\
Sacral width $(\mathrm{mm})$ & $115.53 \pm 8.05$ & $114.11 \pm 9.61$ & 0.756 \\
Sacral angle & $37^{\circ}$ & $27^{\circ}$ & 0.930 \\
Hiatal length $(\mathrm{mm})$ & $25.24 \pm 3.94$ & $24.35 \pm 3.92$ & 0.435 \\
Hiatal width $(\mathrm{mm})$ & $13.47 \pm 2.63$ & $12.31 \pm 2.03$ & 0.645 \\
Hiatal angle & $34^{\circ}$ & $34^{\circ}$ & \\
\hline
\end{tabular}

Table 4 Measurement results on MR images between the ages of 40-49.

\begin{tabular}{llll}
\hline Variable & \multicolumn{2}{c}{ Gender } & $p$ \\
\cline { 2 - 4 } & Male & Female & 0.602 \\
Sacral length $(\mathrm{mm})$ & $109.32 \pm 14.16$ & $106.66 \pm 9.01$ & 0.404 \\
Sacral width $(\mathrm{mm})$ & $118.25 \pm 5.76$ & $119.00 \pm 97.42$ & 0.561 \\
Sacral angle & $26^{\circ}$ & $27^{\circ}$ & 0.121 \\
Hiatal length $(\mathrm{mm})$ & $33.55 \pm 6.10$ & $21.37 \pm 5.12$ & 0.231 \\
Hiatal width $(\mathrm{mm})$ & $16.27 \pm 3.89$ & $13.86 \pm 3.04$ & 0.939 \\
Hiatal angle & $33^{\circ}$ & $37^{\circ}$ & \\
\hline
\end{tabular}

\section{References}

[1] Arınc1, K., and Elhan, A., 2006. Anatomi, 1. Cilt, Güneş Kitabevi, Ankara, 58-63, 124-6.

[2] Sarsilmaz, M. 2000. Anatomi Sistemler, Nobel Yayın Dağıtım, Ankara, 26.

[3] http://www.drismailkocager.com/tedavi/85-kaudal-blok-( -lumber-).html.

[4] Sekiguchi, M., Yabuki, S., Satoh, K., and Kikuchi, S. 2004. "An Anatomic Study of the Sacral Hiatus: A Basis for Successful Caudal Epidural Block.” The Clinical Journal of Pain 20: 50-1.

[5] Kumar, V., Nayak, S. R., Potu, B. K., and Pulakunta, T. 2009. "Sacral Hiatus in Relation to Low Back Pain in South Indian Population." Bratisl Lek Listy 110 (7): 436-41.

[6] Brailsford, J. F. 1929. "Deformities of Lumbosacral Region of Spine." British Journal of Surgery 16: 562-627.

[7] Tokpınar, A., Ülger, H., Yılmaz, S., Acer, N., Ertekin, T., Görkem, B. S., and Güler, H. 2018. "Examination of Inclinations in Spine at Childhood and Adolenscence Stage." Folia Morph. 15-5659. doi: 
10.5603/FM.a2018.0053.

[8] Nagar, S. K. 2004. "A Study of Sacral Hiatus in Dry Human Sacra.” J Anat Soc India 53 (2): 18-21.

[9] Edward, W. B., and Hingson, R. A. 1942. "Continuous Caudal Anesthesia in Obstetrics." Am. J. Surg. 57: 459-64.

[10] Başaloğlu, H., Turgut, M., Taşer, F. A., et al. 2005. "Morphometry of the Sacrum for Clinical Use." Surg Radiol Anat 27: 467-71.

[11] Goodrich, J. T. "A Historical Review of the Surgical Treatment of Spina Bifida." In The Spina Bifida, Milano: Springer, 37.

[12] Tollanes, M. C., Wilcox, A. J., Stoltenberg, C., Lie, R. T., and Moster, D. 2016. "Neurodevelopmental Disorders or Early Death in Siblings of Children with Cerebral Palsy." Pediatrics 138 (2): :e20160269.

[13] Papadokis, J. L., Zebracki, K., Chlan, K. M., and Vogel, L. C. 2017. "Sexuality in Pediatric Spinal Cord Injury." Top Spinal Cord Inj Rehabil 23 (1): 42-8.

[14] Emirzeoglu, M., Bas, O., Ulcay, T., Colakoglu, S., and Uzun, A. 2001. "Morphometric Evaluation of the Sacrum and Its Variations." Karadeniz Tip Dergisi 14: 133-7. (in Turkish)

[15] Mishra, S. R., Sinhh, P. J., Agrawal, A. K., et al. 2003. "Radiologi and Morphologic Evaluation of the Lateral Sacral Mass." Acta Orthop Traumatol Turc 37: 330-9.

[16] Duman, T. 2009. "Yetişkinlerde Os Sacrumun Çok Kesitli Bilgisayarlı Tomografi İle Morfometrik İncelenmesi." MSc thesis, Selçuk Üniversitesi.

[17] Asher, M. A., and Strippgen, W. E. 1986. "Anthropometric Studies of the Human Sacrum Relating to Dorsal Transsacral Implant Designs." Clin Orthop 203: 59-62.

[18] Comas, J., and Charles, C. 1961. Manual of Physical Anthropology. Illinois, USA: Thomas Springfield, pp 415-6.

[19] Esenkaya, İ., Aluçlu, M. A., Kavaklı, A., et al. 2003. "Radiologi and Morphologic Evaluation of the Lateral Sacral Mass." Acta Orthop Traumatol Turc 37: 330-309.

[20] Cicekcibasi, A. E., Borazan, H., Arican, S., Yılmaz, M. T., and Sakarya, M. E. 2014. "Where Is the Apex of the Sacral Hiatus for Caudal Epidural Block in the Pediatric Population? A Radio-Anatomic Study." J Anesth 28 (4): 569-75.

[21] Najman, I. E., Frederice, T. N., Segurado, A. V., and Kimachi, P. P. 2011. "Caudal Epidural Anesthesia: An Anesthetic Technique Exclusive for Pediatric use? Is It Possible to Use It in Adults? What Is the Role of the Ultrasound in This Context?" Rev Bras Anestesiol 61 (1):
95-109.

[22] Bush, K., and Hillier, S. 1991. "A Controlled Study of Caudal Epidural Injections of Triamcinolone plus Procaine for the Management of Intractable Sciatica." Spine 16: 572-5.

[23] Lanier, V. S., McKnight, H. E., and Trotter, M. 1944. "Caudal Analgesia: An Experimental and Anatomical Study." Am J Obstet Gynaec 47 (5): 633-41.

[24] Nadeem, G. 2014. "Importance of Knowing the Level of Sacral Hiatus for Caudal Epidural Anesthesia." $J$ Morphol Sci 31 (1): 9-13. doi: 10.4322/jms.ao053913.

[25] Senoglu, N., Senoglu, M., Oksuz, H., Gumusalan, Y., Yuksel, K. Z., Zencirci, B., Ezberci, M., and Kizilkanat, E. 2005. "Landmarks of the Sacral Hiatus for Caudal Epidural Block: An Anatomical Study.” Br J Anaes 95 (5): 692-5.

[26] Wang, L. Z., Hu, X. X., Zhang, Y. F., and Chang, X. Y. 2013. "A Randomized Comparison of Caudal Block by Sacral Hiatus Injection under Ultrasound Guidance with Traditional Sacral Canal Injection in Children." Paediatr Anaesth 23 (5): 395-400.

[27] Stitz, M. Y., and Sommer, H. M. 1999. "Accuracy of Blind versus Fluoroscopically Guided Caudal Epidural Injection.” Spine 24 (13): 1371-6.

[28] Duncan, M. A., Sherriff, M., O'Keeffe, D., and Dangerfield, P. H. 2009. “A Radiographic Assessment of the Distances from the Sacral Hiatus to the Lower Lumbar Spinous Processes." Eur. J. Anat. 13 (10): 19- 22.

[29] Rita, K., Kumari, S., Prasad, A., et al. 2016. "An Anatomical Study of Variations of Sacral Hiatus and Its Clinical Correlation." IOSRJDMS 15: 18-21.

[30] Shinde, V. K., and Shirbadgi, S. A. 2016. "Study of Variations in Levels of Sacral Hiatus." Int J Anat Res. 4: 1882-5.

[31] Desai Rajeev, R., Jadhav Surekha, D., Doshi Medha, A., et al. 2014. "Variations in Anatomical Features of the Sacral Hiatus in Indian Dry Sacra." Int J Med Res Health Sci. 3: 634-8.

[32] Seema, S. M., and Mahajan, A. 2013. "An Anatomical Study of Variations of Sacral Hiatus in Sacra of North Indian Origin and Its Clinical Significance." Int J Morphol. 31: 110.

[33] Rajani, S. 2017. "Anatomical Variations of Sacral Hiatus and Associated Clinical Relevance-A Review." Int $J$ Anat Var. 10 (4): 96-8.

[34] Ahmm, K., Ara, S., Ashrafuzzaman, M., et al. 2009. "Morphometry of sacral hiatus and its clinical relevance in caudal epidural block." Surg Radiol Anat. 12;31(10):793-800. 